\title{
Developing Integrated Mobile Applications to Provide Culturally Responsive Support for Minnesota African Diaspora and West African Families Impacted by Ebola Virus Disease
}

\author{
Remi Douah, Anuj Kacker \\ Center for Design in Health, College of Design, University of Minnesota, Minneapolis, Minnesota
}

\section{Email address:}

doua0003@umn.edu (R.Douah)

\section{To cite this article:}

Remi Douah, Anuj Kacker. Developing Integrated Mobile Applications to Provide Culturally Responsive Support for Minnesota African Diaspora and West African Families Impacted by Ebola Virus Disease. Science Journal of Public Health. Special Issue: Spatial Analysis and Mathematics in Health Research, during Times of Global Socio-Economic Instability. Vol. 3, No. 3-1, 2015, pp. 10-17.

doi: $10.11648 /$ j.sjph.s.2015030301.13

\begin{abstract}
In recent years, Minnesota has witnessed a huge influx of immigrants from Africa. According to the 2008 Institute for Agricultural and Trade Policy report, Minnesota has become the home of largest population of Somalian in the United States, and the home of the ninth largest population of African immigrants in America. It is estimated that between 70,000 and 80, 000 live in Minnesota. Somalia lead the way with about 37\% of the African population followed by Ethiopia, 21\%, Liberian, $12 \%$, and Kenyan, 8\% (Institute for Agricultural and Trade Policy, 2008). Consequently, the Ebola outbreak in West Africa has impacted the lives of the Minnesota African Diaspora and their relatives living in Africa. The Minnesota African Taskforce Against Ebola (MATFAE) was created as a result of the strong desire among Africans in the Diaspora to address stigma associated with Ebola in Minnesota and provide needed supports to their relatives in Ebola impacted countries. This paper examines the development of a series of integrated mobile applications designed to foster collaboration between the Minnesota African Diaspora and their counterpart in Africa. The Mobile Apps could allow members of the African Diaspora and international community to engage with the Minnesota African Taskforce Against Ebola (MATFAE) as partners to address emergency preparedness and response issues. Those Apps could also serve as a platform for local and global community dialogues to improve health outcomes in Ebola impacted regions.
\end{abstract}

Keywords: mHealth App, Emergency Preparedness, Ebola, Geo-Location, Human Centered Design, African Diaspora

\section{Introduction}

\subsection{Short Background}

Recent Ebola outbreak in West Africa has created havoc and taken the lives of thousands of Africans especially in Liberia, Guinea, and Serra Leone; leading health officials in West Africa to call for massive international responses to contain and stop the spread of the disease [1]. Thus, local and international agencies such as World Health Organizations (WHO), the Center for Disease Control (CDC), NGOs, including Medecins Sans Frontieres International and Red Cross, have rightfully responded to the plight of Ebola victims [2]. The focus of those agencies was mainly patient and aid personnel centered. In other words, attention was manly given to the two group of people (patient and aid personnel) facing this deadly disease [3].

However, it is important to note that the African Diaspora also responded to the call to ease the pains of their brothers and sisters individually and collectively through its moral and financial contributions to support loves ones at home in West Africa. Remittance practices among Africans living in the Diaspora has been a major for of financial and emotional support provided by Africans living outside of Africa [4,5]. In the United States for example, the Minnesota African Taskforce Against Ebola (MATFAE) was created within that context and will be discussed in this paper.

MATFAE was created by West Africans in the Diaspora living in Minnesota to address the Ebola crisis in West Africa. Its main purpose is to educate and work cooperatively with 
local and international organizations to address the immediate needs of medical staff and facilities in Ebola impacted regions in West Africa, namely, Guinea, Liberia, and Sierra Leone.

\subsection{Introducing the need and purpose of this report}

In recent years the world has witnessed a proliferation of mobile health technology to address health issues [6]. A quick search on Google App store on that subject brings about 466,000 results for mobile health applications. Drilling further down on the topic mobile health and Africa for example, one finds a wide range of tools ranging from maternal health to HIV/AIDS prevention.

Last March 2014, the massive outbreak of Ebola virus in multiple countries in West Africa (Liberia, Serra Leone, Guinea and Nigeria), took the international community by surprise. Consequently, questions quickly were raised by experts about the use of mHealth technology for health promotion and education to combat Ebola given the ubiquitous nature of mobile device usage in Africa. Unfortunately, much to experts' surprise, the list of mHealth technology was very short, prompting the mHealth industry to call for more mHealth applications as a viable tool that could contribute to stop the spread of Ebola [7]. Thus, on its website publication of October 2014, mHealth News, the voice of mobile healthcare, published an article entitled Ebola outbreak: Where are the mHealth apps? The author made a desperate call for more design and development of mHealth applications to fight Ebola.

This current article responds to the call to address the lack mhealth Apps to combat Ebola and aims to fill this gap by describing the software development of a series of integrated Mobile Applications designed to provide culturally responsive support for Wes African families living in Minnesota who have been emotionally and psychologically impacted by Ebola.

Also, this paper will examine the role of the Minnesota African Taskforce Against Ebola (MATFAE) and its efforts to serve as a critical partner and a bridge to local and international agencies in the fight against Ebola here in Minnesota and in Africa [8]. The general hysteria, phobia, misinformation, lack of adequate preparation to deal with Ebola, coupled with the lack of accurate and purposeful information dissemination strategies; led to unnecessary discrimination and stigmatization among the African Diaspora living in Minnesota $[9,10]$.

Attention will be given to the development of a series of Mobile Applications that have been designed to support and manage local and global activities of the MATFAE. Those Apps could be used to address emergency preparedness and response issues. They could also serve as a platform for local and global community dialogues to improve health outcomes in Ebola impacted regions in West Africa. Those Mobile Applications were designed using key public health and epidemiological principles along with social network theory [11].

\section{2. mHealth in Africa and the African Diaspora}

In 2011, the International Telecommunication Union reported about 6 billion mobile phones in use Worldwide. Africa has its share of mobile phone usage thanks to recent investment in telecommunication infrastructure. Such efforts have facilitated the surge of mobile devices among Africans. Broadman (2007) for example points out that "the Chinese telecom giant Huawei won contracts worth $\$ 400$ million to provide cell phone service in Kenya, Zimbabwe and Nigeria." Such massive investment has created an unprecedented proliferation of mobile applications in Africa [12].

Thus, the Global Alliance for Chromic disease observed that "Africa now has over 650 million mobile phone subscribers, which is more than both the USA and EU." The same source points out that in Africa, $63 \%$ of the population uses mobile phones even though only $16 \%$ have access to the Internet. This phenomenon has led some observers to The ubiquity of mobile phones which gives users the chance to be connected and become part of a larger network, and in so doing increase the chances of healthcare professionals to send and receive health promotion and education material for prevention purposes.

However, even though researchers have witnessed tremendous expansion in mobile phone market in Africa, such growth has been limited to projects focusing on neo natal health and communicable diseases. No mHealth projects have focused on engaging both Minnesota African Diaspora and their relative in impacted Ebola regions to collaborate and provide culturally appropriate support to address Ebola.

Epimap24 Inc., a Minnesota-based public health emergency preparedness company, has designed and implemented as series of interconnected mobile applications and web portal solutions to support the work of the Minnesota African Taskforce against Ebola (MATFAE) and West African families in Minnesota impacted by Ebola virus disease (EVD) (Figure 1).

Mobile devices such as smart phones are commonly used by African populations around the world. The proposed mobile applications and web portal will connect professional organizations, individuals and communities impacted by EVD. Participants and those served by the applications and web portal (platform) include and are not limited to:

- African Diaspora communities that reside in Minnesota and the entire United States

- Africans living in Africa

- Faith-based leaders

- The Psycho-Social Stigma subcommittee

- Subject matter experts

- Minnesota Department of Health

- Foundations

- Academic Institutions

- Others

Together, the platform will enable efficient, timely communication, information sharing and analytics to improve 
support and outcomes of all communities impacted by EVD. App and web portal use will enable reporting and tracking of information in real-time, support efficient collaboration, and help address the psycho-social stigma that has resulted from the Ebola outbreak in Liberia, Guinea, and Sierra Leone.

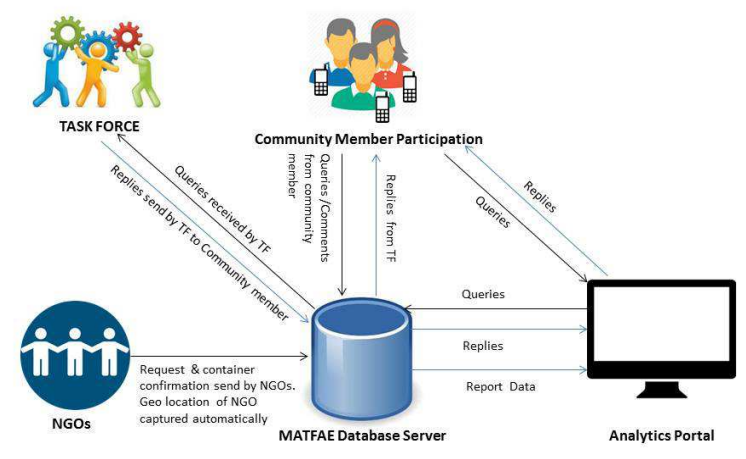

Figure 1. MATFAE Communications Flow in Context of the Proposed Platform.

\subsection{A Human-Centered Design Approach to mHealth}

In his work on "global software team", Camel (1999) made reference to several key factors that demarcate traditional software development from global software design and development [13]. Those factors include: distance, time and cultural differences. Although Camel did not talk about the development of mobile devices in general and mHealth Apps in particular in 1999, it is important to note that his point is still relevant today given the fact software engineers more than ever before work in global teams and for a global and diverse audiences.

However, one should also add that software developments are not only made by software engineers, but could be designed by a multi-disciplinary and multi-sectorial team. Camel seems to adopt a "technology-driven" approach which basically lead the end users to figure out the design thinking of the developer(s) [13].

By contrast, Sharon Oviatt (2006) points out [14]: "Human-centered design advocates that a more promising and enduring approach is to model users' natural behavior to begin with, including any constraints on their ability to attend, learn, and perform, so that interfaces can be designed that are more intuitive, easier to learn, and freer of performance errors". Oviatt goes on to state, "To advance next-generation interfaces, human-centered design that incorporates cognitive science, linguistics, and other areas involving multidisciplinary expertise becomes an inescapable requirement". Implicit in Oviatt remarks are the notions that one has to create an inter-disciplinary and cross-sectorial team to facilitate such design. Understanding the richness, strength and diversity of the team along with cultural differences of the target audiences for which a software is designed can increase the success of its implementation.

Also, implicit in Oviatt comment is the advice to engage with end users of the system in a participatory approach to gain some insight about their cultural belief system and practices. Consequently, understanding cultural belief systems and practices in Africa could also help us comprehend people's attitudes and responses to mHealth Application [14].

\section{Applications and Features}

Proposed applications (apps) are defined and illustrated below:

Mobile Applications - MATFAE offers mobile applications for the following:

- Community Members

- Task Forces

- NGOs

MATFAE Community Members' Mobile App - Community Members can download and install this free mobile app from Google Play Store (https://play.google.com/store/search?q=Epimap247\&c=apps) [15] from anywhere in the world and use it to communicate directly with MN-African Task Force in case of any health crisis. Community members can send their queries under various categories like Food Shelf, Orphans, Psycho Social Stigma, Public Health, Public Engagement and Others. While sending their queries to task force the community members can also click and attach pictures to their queries. This app automatically captures the geo location of the community member while the query or comment is being sent. MAFTAE app further empowers the community member with information on Achievements, Future Plans \& News Feed of MN-African Task Force. Alternatively community members who do not have a smart phone can also contact task force from the website and send their queries and comments.

The Community app automatically captures the geographic location of the community member user when the query or comment is sent. In addition, the app gives users relevant information such as Achievements, Future Plans, and the MATFAE news feed.

MATFAE Task Force's Mobile App (Figure 2, Figure 4): Task Force members can download and register themselves on this app. Their registration request is verified and activated by the Task Force admin who can assign sub-committee roles to the registered members. Based on the sub-committee category(s) assigned to a member, they can receive queries/comments related to assigned categories directly on their smart phones from the community members and can quickly reply back to them. Task Force members can also reply to the queries of community members from their website portal logins. Besides the Task Force members can also see geo location and analytics reports on their portal logins. Task Force mobile application also enables Task Force members to receive support requests, comments and consignment/container receipt confirmations from NGOs.

MATFAE NGO's Mobile App (Figure 3, Figure 4): As the 
names suggest the NGO app enables them to reach out to Task Force anytime and send support requests or comments. NGOs can also send confirmation of consignment/container receipt along with camera snapshot from their app to the Task Force. The NGO app captures real time geo location of the NGO every time a request or confirmation is sent, thus enabling Task Force to know the exact location of NGO on the map from where the support request or consignment/container receipt confirmation has been made.

Web Portal - MATFAE offers a comprehensive web portal with logins for

- Community Members

- Task Forces.

MATFAE Community Members' Web Portal Login -
Community members who do not have smart phones can register on MN-African Task Force Against Ebola at www.mnebolataskforce.com and can send their queries or comments to the Task Force and seek replies and support. Besides they can also access information about achievements, future plans \& newsfeed of Task Force from time to time.

MATFAE Task Force Members' Web Portal Login - Task Force members can use the portal to reply to queries from community members or read their comments. Task Force can review geo location based analytics reports.

Community members who do not have smart phones can contact the taskforce from the website and use the site to send queries and comments.

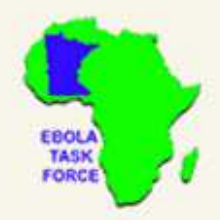

\section{MATFAE MOBILE APP SCREENSHOTS}

\section{Mobile Application Screenshots}

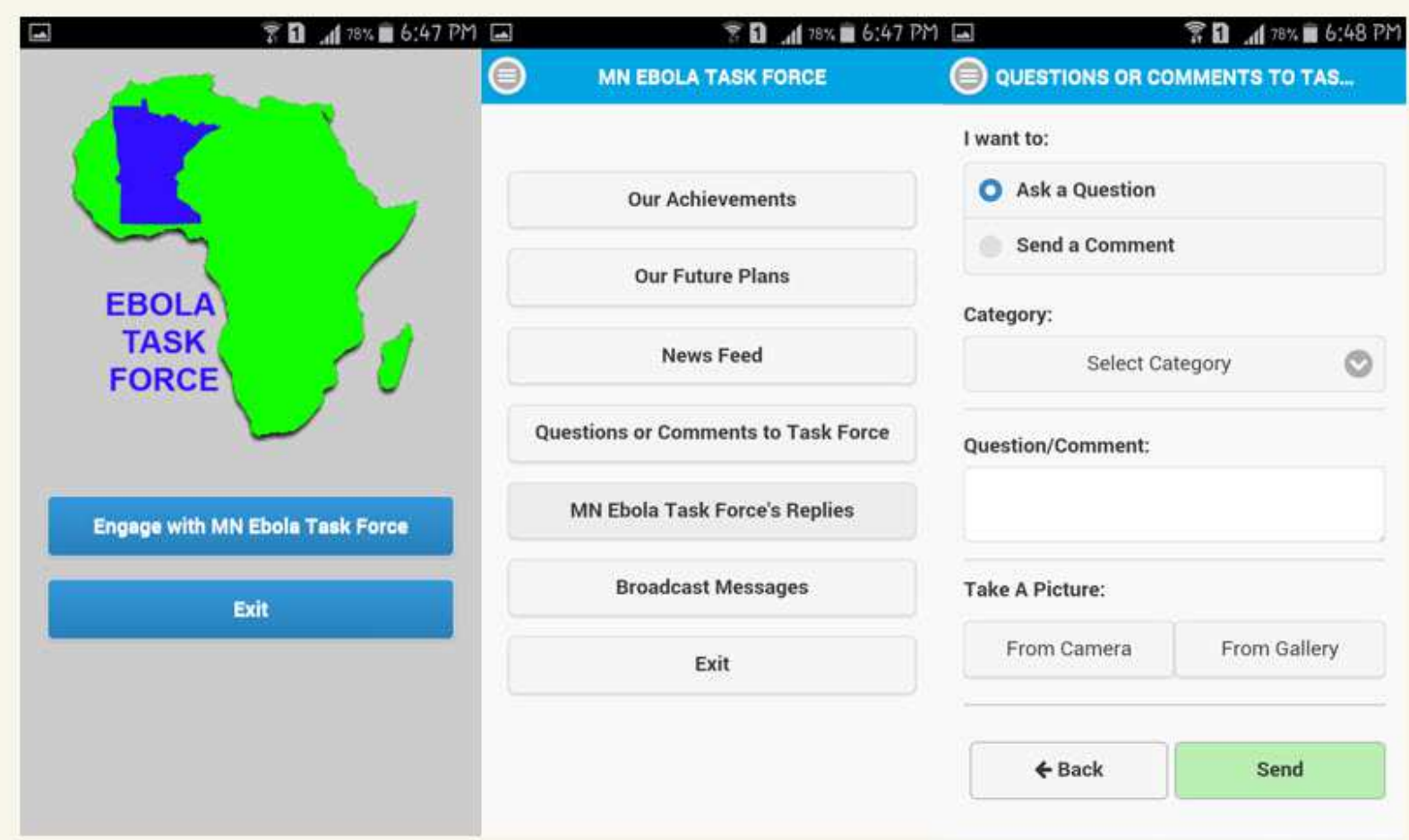

Community Members' Mobile Application

Figure 2. MATFAE Task Force's Mobile App: Community members' mobile application. 
14 Remi Douah and Anuj Kacker: Developing Integrated Mobile Applications to Provide Culturally Responsive Support for Minnesota African Diaspora and West African Families Impacted by Ebola Virus Disease

\section{MATFAE MOBILE APP SCREENSHOTS}

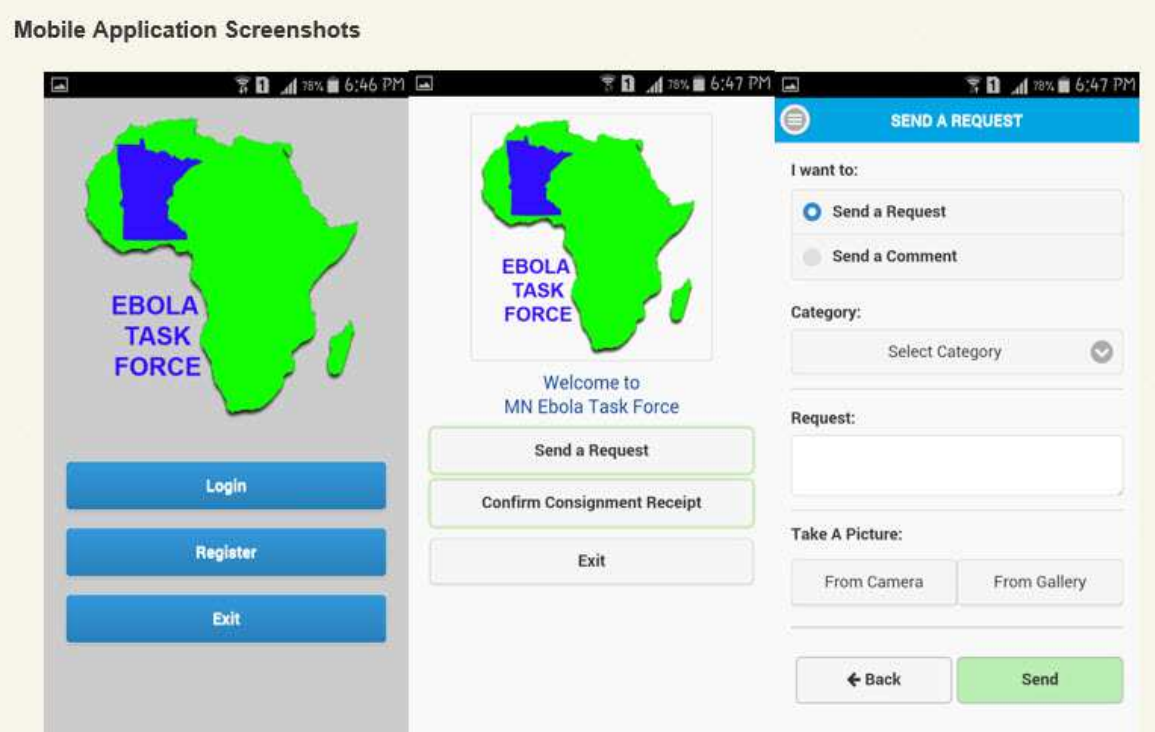

NGOs' Mobile Application

Figure 3. MATFAE Task Force's Mobile App: NGOs' mobile application.

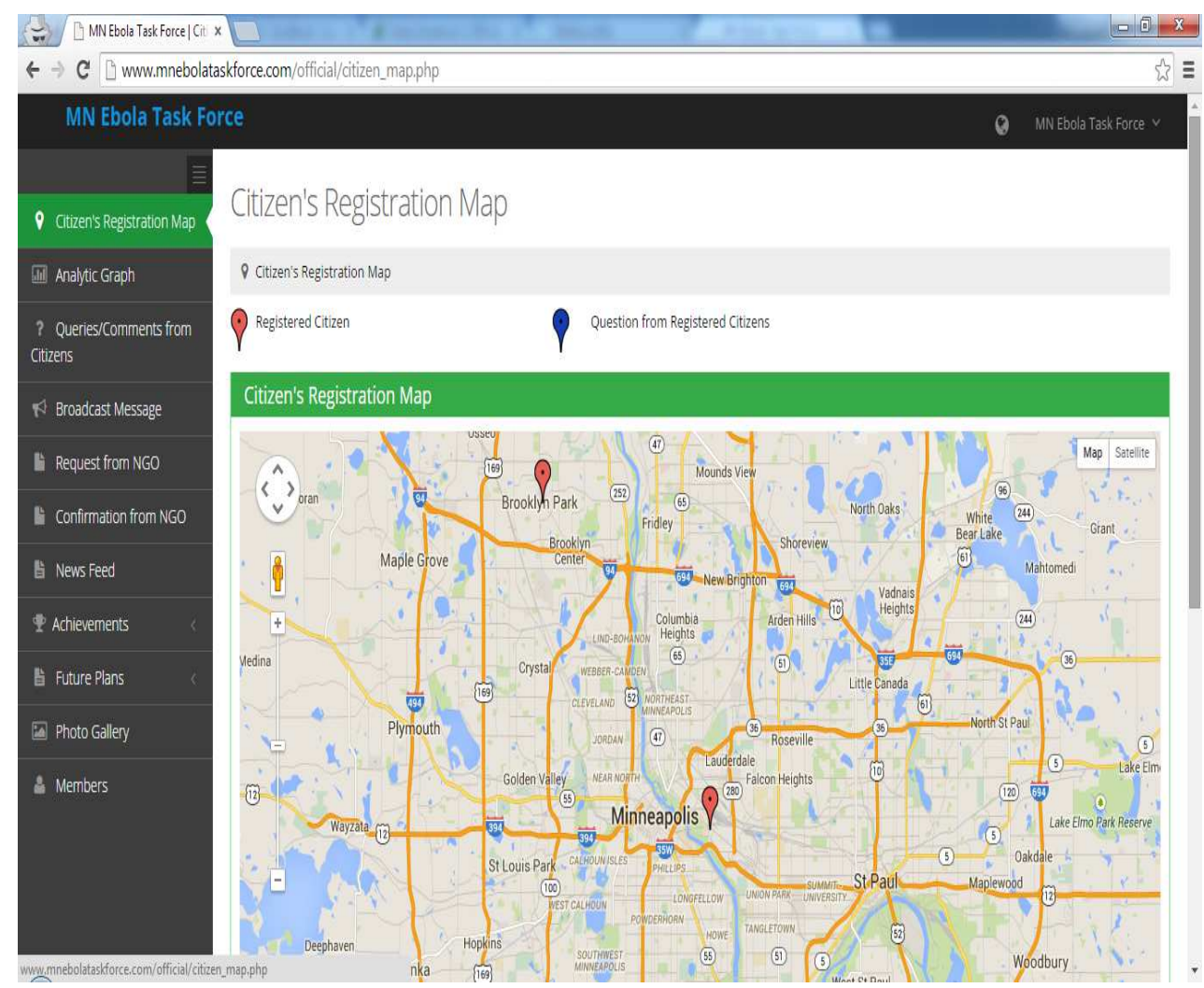

Figure 4. Sample Geo-Location Report. 


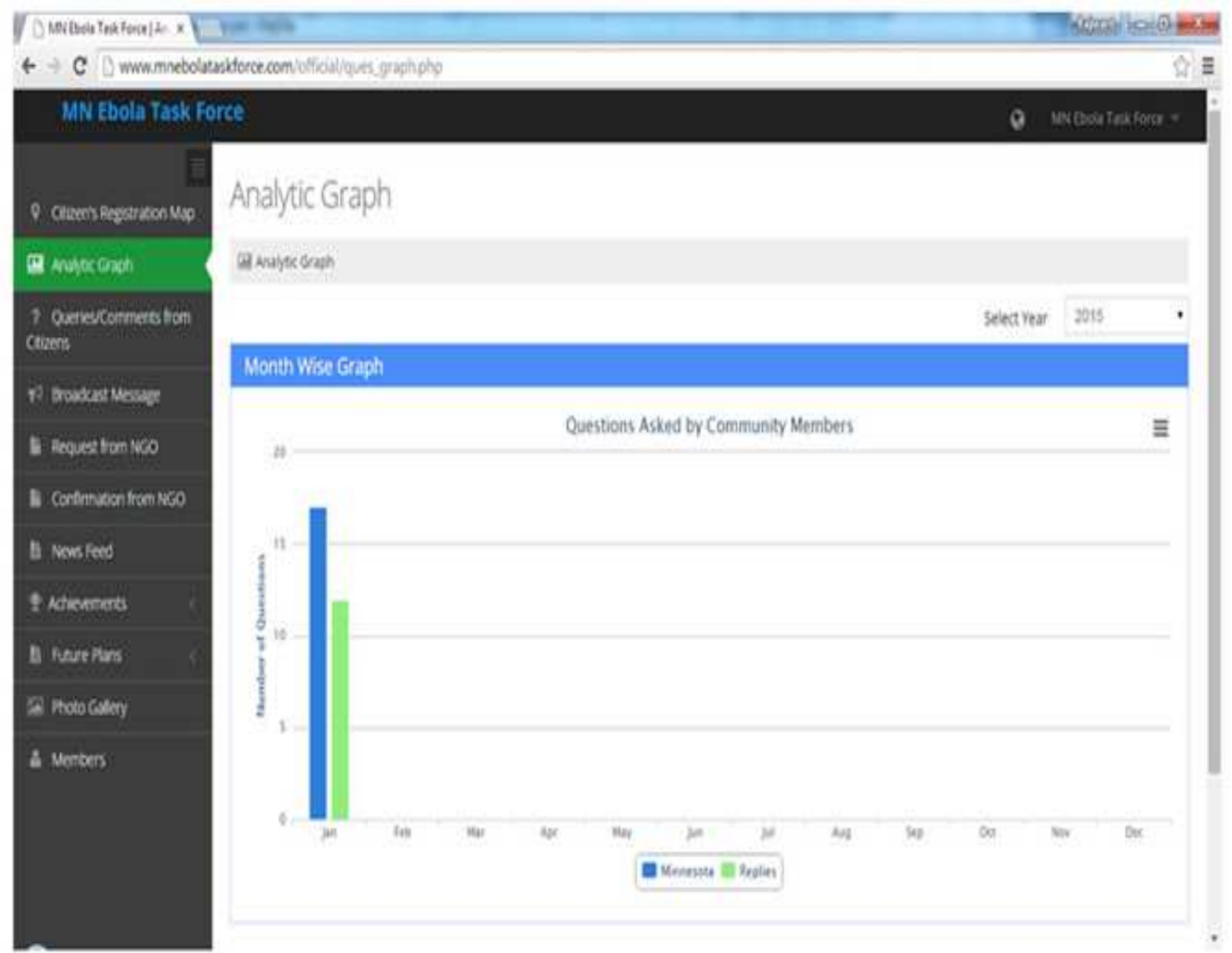

Figure 5. Sample of the evaluation report.

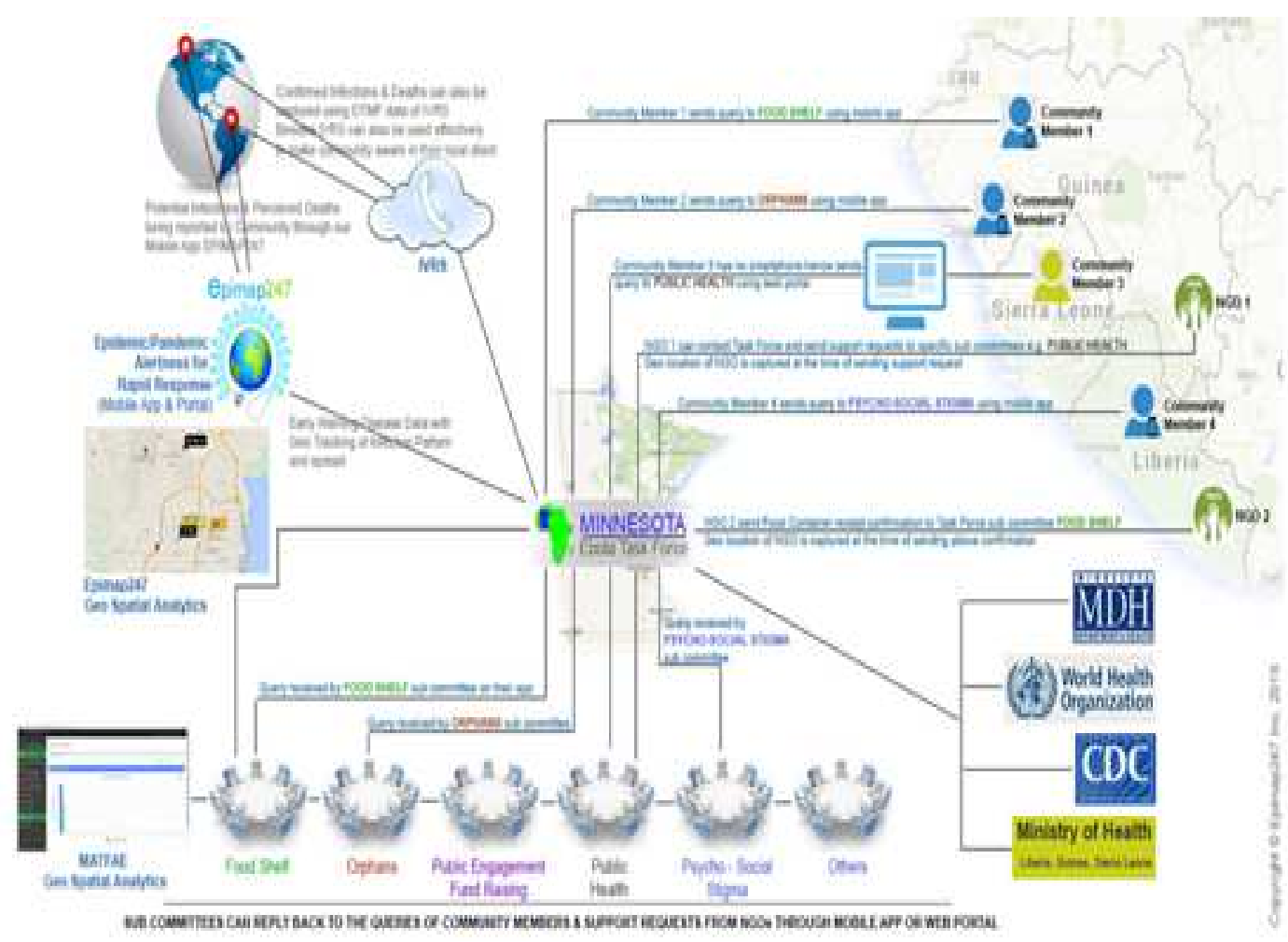




\subsection{Benefits}

The proposed platform offers the value and benefits listed below (Figure 6):

1. Gives Africans and their families impacted by EVD and residing around the world a way to share observations, insights, information and questions

2. Offers the African Diaspora and Africans residing in Africa a platform to connect directly with faith-based leaders, mental health subject matter experts, and MATFAE

3. Provides culture-centric resources to individuals impacted by psycho-social stigma associated with EVD

4. Contributes to building community trust with MATFAE and African Diaspora

5. Enables members to access culture-centric counseling and assistance

6. Facilitates communication among MATFAE taskforce members

7. Supports transparency

8. Builds a data set that supports analysis and enables leaders and organizations to measure impact of outreach and information sharing initiatives.

9. Enables real-time communication between community members and health agencies

10. Enables easy access to resources: applications can be downloaded from anywhere in the world for free using Google Play Store.

In addition, MATFAE can track its responsive rates and response accuracy to community member inquiries and requests. For example, the Psychosocial Stigma committee can use the platform to coordinate communications between community members, faith-based leaders, and subject matter experts.

\subsection{About the Minnesota African Task force against Ebola (MATFAE)}

The MATFAE was created in August 2014 in response to the needs and concerns of the massive Ebola pandemic, The Minnesota African Task force Against Ebola (MATFAE) members consist of people not only from Guinea, Liberia, and Sierra Leone, but persons from the African Diaspora, including friends of Africans.

MATFAE has taken the lead to organize and facilitate several awareness forums on Ebola, including the first Ebola walk and supply drive to assist persons impacted in Ebola regions. The MATFAE has also advocated and lobbied on both state and federal levels for addressing current and emergent needs for the African Diaspora living in Minnesota. MATFAE is made of various committees. They include: Food shelf, Orphans, Public engagement and fund raising, psychosocial stigma, and outreach. The integrated Mobile Applications discussed in this article will help connect the African Diaspora to fight against Ebola and help facilitate every day communications among the task force and subcommittees. MATFAE meets up to two times weekly for strategic planning such as ongoing food drive, updates regarding Ebola, and strengthening health systems in post Ebola and the role of the African Diaspora locally in the US and around the world.

It is important to note that the Task Force works closely with and benefited from initial efforts involving community groups such as the Brooklyn Park Fire Department, the cities of Brooklyn Park and Brooklyn Center. The Minnesota Department of Health, Hennepin County, along with other stakeholders have been working together with MATFAE since the beginning of Ebola pandemic and planned information sessions to educate and inform the public about the Ebola outbreak [16].

Mobile Apps that will allow members of the African Diaspora and international community to engage with the MATFAE as partners to address emergency preparedness and response issues. Those Apps could also serve as a platform for local and global community dialogues to improve health outcomes in Ebola impacted regions.

\section{Additional Considerations}

\subsection{Impact on Public Health and Financial Sustainability}

Development and implementation of the proposed integrated mobile applications can be used to identify members of the Minnesota African Diaspora in need of mental health treatment. Second, the applications provide a platform to educate and diffuse cultural-centric health promotion materials in multiple African languages. As a result of impacted communities receiving actionable, meaningful information, public health outcomes can be impacted positively.

\subsection{Financial Considerations}

Being able to define the cost and magnitude of mental illness and treatment has been of primary interest to health agencies across the United States, such as the National Institute of Mental Health. Recent research on mental health epidemiology shows that tens of millions of people each year are affected by mental illness and care access disparities. According to the National Institute of Mental Health, "only about half of those affected receive treatment."

The recent Ebola outbreaks in Liberia, Guinea, Liberia and Nigeria have had a massive effect on the African Diaspora living in Minnesota and the United States generally. Reaching and serving such populations has been challenging for health care providers. Barriers include language, lack of culturecentric information and services, and lack of a central source of information that helps ensure consistently accurate information is provided. The recent Minnesota Department of Health taskforce notes that Minnesota has the largest immigrant and refugee communities. Up to $\$ 63$ million in savings can be realized by: 
- Engaging the estimated $250-400$ unlicensed immigrant physicians in Minnesota

- Developing and implementing cultural-centric, multilingual mobile applications; the apps can be used to identify and provide care to otherwise hard-to-reach immigrant populations

Every dollar invested in innovative and integrated mobile applications to support Culturally Responsive Psychosocial and Bereavement Support Service for West African Families in Minnesota impacted by the Ebola Virus Disease will result in savings reported by the Minnesota Department of Health (MDH) taskforce in the following decade.

\section{Conclusions}

The ubiquity of Mobile apps in recent years has forced health officials locally and globally to make mHealth a critical emergency telecommunications tool for responding to epidemics such as Ebola. It helps facilitate and coordinate emergency response crisis and provides local and international communities with real time access trustworthy information from trusted official agencies such as World Health Organization (WHO), and the Center for Disease Control, to name a few [17-19]. The integrated mobile applications presented in this paper can help facilitate collaboration and coordination among organizations responding to the Ebola crisis and offers the general public access to the latest Ebola news from official sources, including real time interactive maps.

Finally, the African Diaspora [20] can play a critical role to discriminate trustworthy health promotion messages that can enhance prevention, and improve health outcomes in impacted Ebola regions. Using innovative and integrated mobile applications can be a great asset for emergency preparedness officials locally and globally.

\section{References}

[1] Zielinski, S. (2014). Ebola crisis reveals gaps in public health response. Science, 346(6209), 563-564. Available at: http://tc.liblink.umn.edu/sfx_local?ctx_ver=Z39.88-

2004\&url ver $=Z 39.88$ -

2004\&ctx_enc $=$ info $\% 3$ Aofi $\% 2$ Fenc $\% 3$ AUTF-

8\&ctx_id=10_1\&rft.auinit $=$ S\&rft.volume $=346 \&$ rft.issn $=0036-$ $8075 \&$ rft.genre $=$ article \&rft.issue $=6209 \&$ rft.pages $=563-$

564\&rft.eissn $=1095$ -

9203\&rfr_id=info\%3Asid\%2Fwww.exlibrisgroup.com\%3 Abxmenu\&rft.stitle=SCIENCE\%20MAGAZINE\&rft.aufirst=Sara h\&rft_id=urn $\% 3 \mathrm{Abx} \% 3 \mathrm{~A} 93508086 \&$ rft.atitle $=$ Ebola $\% 20$ crisis $\% 20$ reveals $\% 20$ gaps $\% 20 \mathrm{in} \% 20$ public $\% 20$ health $\% 20$ response. $\&$ rft.aulast $=$ Zielinski\&rft.jtitle $=$ Science $\&$ rft.coden $=$ SCIEAS\&r ft.date $=2014-10$ -

$31 \& \mathrm{rft} . \mathrm{au}=$ Zielinski\%2C $\% 20$ Sarah\&rft.epage $=564 \& \mathrm{rft}$.spage $=$ 563\&rft.auinit1=S\&rft.object_id=954925443632\&rft_dat=urn \%3Abx\%3A93508086\&rft_val_fmt=info:ofi/fmt:kev:mtx:jour nal\&sfx.previous_request_ $\overline{\mathrm{id}}=3 \overline{3} 268369$

[2] Zahn, L. M. (2014). Evolution of ebola virus over time. Science, 345(6202), 1306-1306.
[3] Wolz, A. (2014). Face to face with ebola - an emergency care center in sierra leone. $N$ Engl J Med, 371(12), 1081-1083. doi:10.1056/NEJMp1410179

[4] Brown, S. S. S. (2006). Can remittances spur development? A critical survey. International Studies Review, 8(1), 55-75.

[5] Page, J., Page, S., \& Plaza. (2006). Migration remittances and development: A review of global evidence. Journal of African Economies, 15(suppl 2), 245-336. doi:10.1093/jae/ej1035

[6] Kaplan, W. A. A. (2006). Can the ubiquitous power of mobile phones be used to improve health outcomes in developing countries? Globalization and Health, 2(9), 9-9.

[7] Hersh, W., Margolis, A., Quiros, F., \& Otero, P. (2010). Building a health informatics workforce in developing countries. Health Affairs (Project Hope), 29(2), 274-277. doi:10.1377/hlthaff.2009.0883

[8] Minnesota African Ebola Task force. The taskforce's full report and recommendations are available at http://mnebolataskforce.com/ http://www.health.state.mn.us/divs/orhpc/workforce/iimg/finalr pt.pdf (PDF: 1747K/ 84 pages).

[9] Gronke, P. (2015). The Politics and Policy of Ebola. PS: Political Science \& Politics, 48(01), 3-18.

[10] Pietrzak-Franger, M. M., \& Holmes, M. S. (2014). Disease, communication, and the ethics of (in) visibility. Journal of bioethical inquiry, 11(4), 441-444.

[11] MN Ebola Task force Apps in Google App store. Android phones . Available at: www.play.google.com/store

[12] Broadman (2007) Connecting Africa and Asia is available at http://www.imf.org/external/pubs/ft/fandd/2007/06/broadman.h tm.

[13] Erran Carmel (1999). Global Software Teams: Colloborating Across Borders and Time Zones. Prentice Hall PTR.

[14] Sharon Oviatt (2006). Human-centered design meets cognitive load theory: designing interfaces that help people think. Is available at Multimedia ' 06 ' proceedings of the $14^{\text {th }}$ annual ACM international conference on multimedia.

[15] MATFAE Community Members' Mobile App. Available at: https://play.google.com/store/search?q=Epimap247\&c=apps

[16] Minnesota Department of Health. MDH. Available on the $\mathrm{MDH}$ :

http://www.health.state.mn.us/divs/orhpc/workforce/iimg/inde x.html

[17] Green, A. (2014). WHO and partners launch ebola response plan. Lancet (London, England), 384(9942), 481-481.

[18] Global Alliance for Chronic Diseases is available at http://www.nhlbi.nih.gov/about/org/globalhealth/alliancechronic-diseases/index.htm

[19] Tracey, L. E., Regan, A. K., Armstrong, P. K., Dowse, G. K., \& Effler, P. V. Letter to the editor: Management of patients with Ebola virus disease in Europe: high-level isolation units should have a key role Management of pregnant women infected with Ebola virus in a treatment centre in Guinea, June 2014.

[20] Arthur, J. A. (2000). Invisible sojourners: African immigrant diaspora in the United States. Greenwood Publishing Group. 